\title{
Transgenic medaka fish which mimic the endogenous expression of neuronal kinesin, KIF5A.
}

\section{$\operatorname{AUTHOR}(\mathrm{S}):$}

Kawasaki, Takashi; Kurauchi, Kanta; Higashihata, Akira; Deguchi, Tomonori; Ishikawa, Yuji; Yamauchi, Masatake; Sasanuma, Motoe; ... Wakamatsu, Yuko; Yuba, Shunsuke; Kinoshita, Masato

\section{CITATION:}

Kawasaki, Takashi ...[et al]. Transgenic medaka fish which mimic the endogenous expression of neuronal kinesin, KIF5A.. Brain research 2012, 1480: 12-21

\section{ISSUE DATE:}

2012-10-22

URL:

http://hdl.handle.net/2433/160396

\section{RIGHT:}

C 2012 Elsevier B.V.; この論文は出版社版でありません。引用の際には 出版社版をご確認ご利用ください。; This is not the published version. Please cite only the published version. 
Transgenic medaka fish which mimic the endogenous expression of neuronal kinesin, KIF5A.

Takashi Kawasaki ${ }^{1}$, Kanta Kurauchi ${ }^{2}$, Akira Higashihata ${ }^{2}$, Tomonori Deguchi ${ }^{1}$, Yuji Ishikawa ${ }^{3}$, Masatake Yamauchi ${ }^{4}$, Motoe Sasanuma ${ }^{4}$, Hiroshi Hori ${ }^{5}$, Makiko Tsutsumi ${ }^{5}$, Shunsuke Yuba ${ }^{1}$ and Masato Kinoshita ${ }^{\S 2}$

${ }^{1}$ Health Research Institute, National institute of Advanced Industrial Science and Technology (AIST), Nakoji, Amagasaki 661-0974, Japan;

2 Division of Applied Bioscience, Graduate School of Agriculture, Kyoto University, Kitashirakawa-Oiwake-cho, Sakyo-ku, Kyoto 606-8502, Japan;

${ }^{3}$ Division of Biology, National Institute of Radiological Sciences, Anagawa, Inage-ku, Chiba 263-0024, Japan

${ }^{4}$ Genome Research Group, National Institute of Radiological Sciences, Anagawa, Inage-ku, Chiba 263-0024, Japan

${ }^{5}$ Division of Biological Science, Graduate School of Science, Nagoya University, Nagoya 464-8602, Japan

$\S_{\text {Corresponding author }}$

Email address: kinoshit@kais.kyoto-u.ac.jp 


\section{Abstract}

Intracellular transport is spatiotemporally controlled by microtubule-dependent motor proteins, including kinesins. In order to elucidate the mechanisms controlling kinesin expression, it is important to analyze their genomic regulatory regions. In this study, we cloned the neuronal tissue-specific kinesin in medaka fish and generated transgenic fish which mimic endogenous neuronal kinesin expression in order to elucidate the mechanisms which regulate kinesin expression. Searches for medaka neuronal orthologues by RT-PCR identified a candidate gene expressed only in neuronal tissues. Using BAC clones, we determined the cDNA sequence and the gene structure of the candidate neuronal kinesin. Evolutionary analysis indicated that the candidate gene encoded medaka KIF5Aa. The endogenous medaka orthologue was found to be expressed only in the nervous system, including the brain and spinal cord, while expression of KIF5Ab was not exclusive to neuronal tissues.

Transgenic ( $\mathrm{Tg})$ medaka that expressed EGFP under the control of the $6.9 \mathrm{kbp} \mathrm{5}$ ' and $1.9 \mathrm{kbp} 3$ ' flanking regions of the KIF5Aa gene showed characteristic expression throughout the nervous system, including the brain, spinal cord, olfactory pit, eye and cranial nerve. Immunohistological analysis showed that EGFP expression in $\mathrm{Tg}$ fish co-localized with expression of $\mathrm{HuC} / \mathrm{D}$, a neuronal marker. These results demonstrate that the $6.9 \mathrm{kbp} 5$ ' and $1.9 \mathrm{kbp} 3$ ' flanking regions of medaka KIF5Aa have neuronal-specific promoter activity mimicking endogenous expression of medaka KIF5Ab. This transgenic fish strain will be useful for further functional analysis of the effects of these regulatory regions on gene expression. 


\section{Introduction}

Kinesins comprise a large superfamily of microtubule-dependent motor proteins. Kinesins interact with microtubules and move along microtubule rails by coupling to ATP hydrolysis [Brady 1985]. This active movement supports the intracellular transport of organelles, protein complexes and mRNA to the appropriate destination at specific time points, and also regulates mitosis by playing key roles in spindle formation, chromosome segregation, and midbody formation which regulates division of the nucleus, cytoplasm, organelles and cell membrane [Mclntosh et al. 2002, Moore et al. 2004]. During these cellular events, the expression of kinesin molecules must be spatially and temporally controlled. However, the mechanisms which regulate their expression remain to be elucidated.

All kinesin molecules have a highly conserved motor domain within which resides a globular catalytic domain that contains both microtubule- and nucleotide-binding sites [Hirokawa et al. 1989]. The intramolecular position of the motor domain determines the directionality of the motor protein movement [Hirokawa and Noda 2008]. Other regions are more variable, including the filamentous stalk region, which is involved in oligomer formation, and the globular tail region, which binds to cellular cargo directly or indirectly through light chains or binding proteins [Hirokawa et al. 1989, Hirokawa 1998].

Recently, genome database searches have identified 45 kinesin genes in mouse, 38 of which are expressed in the brain [Miki et al. 2001]. Moreover, it was predicted that several mRNAs are transcribed from each of the kinesin genes by alternative splicing. This splicing not only contributes to the diversity of this molecular family but also results in changes to the motor activity, as it has been reported that KIF1B activity is modified by an insertion resulting from splicing [Matsushita et al. 2009]. However, it is unclear how this splicing is regulated to generate molecular diversity and how the expression of each gene product is spatiotemporally controlled.

Gene expression is generally thought to be regulated by mechanisms mediated by cis-acting elements within the regulatory region of the gene with which transcription factors can interact. It was reported that nuclear respiratory factor 1 (NRF1) positively regulates the expression of KIF17, which is involved in the transport of vesicles containing the $\mathrm{N}$-methyl-D-aspartate receptor NR2B subunit, through a highly conserved element [Dhar and Wong-Riley 2011]. Recently, it was reported that the transcription factor Gli can synthesize numerous mRNAs of varying translational efficiency via alternative splicing of non-coding exon in the 5' untranslated region [Palaniswamy et al. 2010]. This suggested that there are other novel mechanisms by which splicing regulates the level of translation. 
Functional deficiency or abnormalities in kinesin regulatory machinery can cause disorders in cellular functions, consequently cause disease. Mutated and functionally deficient kinesins have been reported in many neuronal disorders, including Charcot-Marie-Tooth disease type2 [Crimella et al. 2011], hereditary spastic paraplegia [Wang and Brown 2010], hereditary sensory and autonomic neuropathy type II [Rivière et al. 2011], and schizophrenia [Tarabeux et al. 2010]. Additionally, it has been reported that the pathologic conditions in a polycystic kidney disease mouse model may be caused by the inhibition of KIF12 transcription resulting from a mutation in HNF-1beta, a regulator of Kif12 expression [Gong et al. 2009]. Moreover, numerous studies have suggested a relationship between disorders in kinesin expression and tumorigenesis [Yu and Feng 2010]. Taking these reports into account, it is highly likely that mutations within the regulatory regions of kinesin genes may also be pathogenic.

In this study, we cloned a medaka neuronal kinesin and generated transgenic medaka fish using the regulatory region of the kinesin in order to visualize its endogenous expression. This transgenic fish should be a powerful tool for future functional analysis of the regulatory regions of the neuronal kinesin gene. 


\section{Results}

\subsection{Identification and cloning of medaka neuronal kinesin}

We designed a degenerated primer set based on the sequences of several kinesin genes to explore kinesin expression in neuronal tissues. PCR product amplified by RT-PCR from only brain mRNAs were cloned and sequenced; this was followed by the screening of BAC clones which included the gene of interest to determine the coding region sequence. Analysis of the BAC clones identified that the gene was positioned on medaka chromosome 7. Phylogenetic analysis indicated that the presumptive neuronal kinesin was a medaka orthologue of KIF5A, KIF5Aa (named on the basis of sequence and syntenic homology with zebrafish KIF5Aa; Fig.1A), and is consistent with the expression of mouse KIF5A exclusively in neuronal tissues [Niclas 1994]. Determination of the transcription start site (data not shown) identified that non-coding exons were not present within the gene, thus the orthologue was composed of 29 exons encoding a protein of 1042 amino acids (Fig.1B, Fig.3B).

Medaka KIF5Aa showed high homology with mammalian KIF5A (70\% amino acid similarity with human and mouse), especially within the motor domain, neck and coiled-coil tail, whereas regions showing comparatively lower homology were dispersed in the hinge, coiled-coil stalk domain and the globular tail, similar to previous reports [Miki et al. 2005]. It is suggested that the latter are major targets for alternative splicing (Fig.1B).

Based on sequence analysis it was predicted that the linker region of the tail domain contains one PEST sequence (Fig.1B), known to be involved in protein cleavage by proteases and which is conserved in zebrafish, while in higher vertebrates KIF5A genes have a PEST sequence in the upper position. Cleavage at this site would sever the motor domain from the distal tail domain [Berg et al. 2000].

As shown in Fig.2A, expression of endogenous medaka KIF5Aa was restricted to neuronal tissues including the brain and spinal cord. Temporal expression analysis identified that medaka KIF5Aa was expressed as early as 4 days after fertilization (daf; Fig.2B), when neuronal tissues are undergoing development. Whole mount in situ hybridization showed that endogenous medaka KIF5Aa was expressed throughout the neuronal tissues, including the brain and spinal cord (Fig.4). Staining in the medial region (gray matter) of the spinal cord suggested that medaka KIF5Aa is strongly expressed in axons (Fig.4e).

In medaka fish there are many instances in which there are two functional homologues of the same gene due to prior genome duplication. KIF5Ab was also found in the medaka genome database and was identified in phylogenetic analysis (data not shown). Genomic 
synteny of KIF5Ab more closely resembles that of human KIF5A than that of medaka KIF5Aa (Fig.3A). However, tissue distribution of the KIF5Ab transcript was not completely restricted to neuronal tissues (Fig.2A). Thus we used the regulatory region of the KIF5Aa gene to generate a $\mathrm{Tg}$ fish strain to enable the visualization of neuronal tissues.

\subsection{Phenotypes of $\mathrm{Tg}$ fish}

We established a Tg strain using DNA construct to express EGFP under the control of the $6.9 \mathrm{~kb} 5$ ' and $1.9 \mathrm{~kb}$ 3' flanking region of medaka KIF5Aa. In Tg fishes, EGFP expression was first detected in cells adjacent to the caudal side of the eye, suggesting they may be precursors of the trigeminal ganglion, and was also detected in the spinal cord at 3 daf (Fig.5A). This expression subsequently increased both quantitatively and spatially in all neuronal tissues, and high levels of expression continued throughout the adult stages (data not shown). Tg fishes expressed EGFP throughout the brain, including the telencephalon, olfactory bulb, habenula, mesencephalon, pineal gland, torus longitudinalis, cerebellum and medulla, as well as in the spinal cord (Fig.5B). In the spinal cord, EGFP-positive cell bodies and fibrous structures were observed in both the medial gray matter and in the lateral white matter (Fig.5C). EGFP was also detected in optic nerve and retina (Fig.5D). EGFP expression was identified even in peripheral nervous system, including in characteristic rosette-like formations of the olfactory epithelium, as well as sympathetic trunk and motor neurons (Fig.5B, 5C, 5D). Other peripheral nerves, including cranial nerves were also identified by low-level expression of EGFP (Fig.5D).

\subsection{Identification of cell types expressing EGFP in Tg fish}

In order to identify the specific cell types expressing EGFP in Tg fish, we performed immunofluorescent analysis on sectioned Tg larvae. We used an antibody raised against mouse $\mathrm{HuC} / \mathrm{D}$, a neural-specific marker, which labeled the cytoplasm of neuronal cell bodies, consistent with previous reports [Kasashima 1999, Ekström 2003]. Anti-EGFP immunoreactivity co-localized with that of anti-HuC/D; however, we also observed a subpopulation of cells that was anti-HuC/D-positive but anti-EGFP-negative in both the brain and spinal cord (Fig.6). For example, cells scattered throughout the fibrous layer on the surface of the optic tectum appeared to be anti-EGFP-negative, though they were positive for anti-HuC/D (Fig.6). On the other hand, anti-EGFP immunoreactivity did not co-localize with that of anti-GFAP, a marker for astrocytes (data not shown), which showed a fibrous distribution in the brain and spinal cord similar to the slender cell bodies characteristic of 
astrocytes in the zebrafish brain [Grupp et al. 2010]. We were unable to identify any positive signals for oligodendrocyte markers within either the brain or spinal cord. In a previous report on zebrafish, the pattern of oligodendrocytes was clearly different from the pattern of EGFP observed in the current study [Yoshida and Macklin 2005, Jung et al. 2010]. 


\section{Discussion}

A variety of cellular functions, stimulated by extracellular ligands, are accomplished through the specialized compartmentalization of effector molecules; this ensures that signaling is precisely regulated according to the spatial and temporal pattern of stimulation. Kinesins, which constitute a very diverse family of molecular motors, have been shown to play important roles in such compartmentalization by linking diverse functions, including intracellular transport, mitotic spindle formation, chromosome segregation, midbody formation, and the completion of cytokinesis. KIF5 was implicated in the transport of a number of proteins, including cytoskeletal components, receptor-associated factors, and, in neurons, the synaptosome-associated protein of $25 \mathrm{kD}$ (SNAP25) and SNAP23. KIF5 has also been shown to play important roles in the transport of organelles, such as synaptic vesicles and lysosomes. Furthermore, KIF5A is expressed in all neurons, and is distributed throughout the neuronal cytoplasm, including the cell body, dendrites and axon [Kanai et al. 2000]. These reports suggest that activity of KIF5 may be involved in the maturation or maintenance of cellular signaling pathways, and may be particularly important for transducing neuronal activity. The widespread and stable expression of medaka KIF5Aa in the nervous system, which begins during early developmental stages, suggests that medaka KIF5Aa also contributes to intracellular transport in differentiating and differentiated neurons. However, the mechanisms which regulate kinesin transcription have not been investigated in detail, even though numerous studies have reported on the functions of kinesin molecules. Moreover, few papers have reported the generation of transgenic vertebrates which mimic the expression pattern of endogenous kinesins in order to analyze transcriptional regulatory mechanisms.

In the present study, we searched for the neuronal kinesin gene in medaka, identified and cloned medaka KIF5Aa, and subsequently generated a $\mathrm{Tg}$ strain mimicking the endogenous expression of KIF5Aa. Using this strain it is possible to analyze transcriptional regulation of the neuronal kinesin and visualize neuronal structure and function in a living organism. Identification of KIF5A as a neuronal kinesin is supported by the demonstration that mouse KIF5A is also expressed exclusively within neuronal tissues. Medaka fish have two KIF5A homologues due to a genome duplication event that occurred early in the evolutionary process. KIF5Aa exhibited neuronal tissue-specific expression, while expression of the other homologue, KF5Ab, was not restricted to neuronal tissues (Fig.2A) in spite of higher analogy, in terms of genomic synteny, with the human orthologue (Fig.3A). It is unclear how gene functionalization occurs following genome duplication. Although medaka KIF5Aa and KIF5Ab were expressed at similar levels within neuronal tissues, 
specific neuronal gene expression appears to have been inherited only by the KIF5Aa gene; therefore KIF5Aa is the more suitable gene for analyses pertaining to mechanisms which restrict expression to neurons.

Previous reports have suggested that neuron-specific promoter activity is actualized by neuronal enhancers located upstream of the core promoter, and by non-neuronal repressors within the first intron (Uveges et al. 2002, Zhou et al. 2005, Kouzmenko et al. 1997). However, the latter case does not apply to the regulation of medaka KIF5Aa gene expression as the first intron is not necessary to mimic the endogenous expression pattern of the gene. We identified a TATA box and CCAAT box upstream near the transcription start site (data not shown), although we could not find repressor binding elements such as a neuron-restrictive silencer element. It was reported that the expression of zebrafish HuC, a neuron-specific marker, is regulated by GC boxes upstream of a CCAAT element or TATA like sequence [Zhao et al. 2006, Wang and Bannon 2005]. In the medaka KIF5A gene, GC box-like sequences surround the TATA box and CCAAT box in the region upstream of the transcription start site (data not shown), and may be a component of the regulatory machinery. In mammals, CpG islands regulate tissue- or cell-specific expression through DNA methylation [Ghosh et al. 2010, Chatterjee et al. 2012], and recent reports have suggested that this mechanism is conserved in lower vertebrates including fish [Elango and Yi 2008, Aluru 2010]. The 5' flanking region used in this study includes two putative CpG islands in regions proximal and distal to the translation initiation site (data not shown), and thus are also possible candidates for playing a role in regulating tissue-specific expression of medaka KIF5Aa. Although it has not been verified if the 3'-flanking region is essential for mimicking the endogenous expression pattern of KIF5Aa, it may be important for proper KIF5Aa tissue-specific expression, as reported previously [Tanaka et al. 2001].

Errors in kinesin expression, as well as kinesin function, can result in cell death, cellular functional abnormalities, and cancer (Yu and Feng 2010). This suggested a relationship between kinesin expression, tumorigenesis and cancer progression. The use of $\mathrm{Tg}$ fish for visualizing kinesin expression may be a valuable tool for enhancing cancer research and the exploration of therapeutic agents by linking mutagenesis, gene expression and phenotype.

Tg medaka fish that express EGFP under the control of the KIF promoter may also be utilized in pathological and therapeutic analyses. Recently, it was reported in mouse brain that repeated methamphetamine administration alters the expression of the NMDA receptor channel epsilon2 subunit and KIF17, a neuron-specific molecular motor [Yamamoto et al. 2006]. Behavioral sensitization related to abuse and/or relapse may be associated with stable changes in gene expression; therefore these two molecules are candidates for such responsive genes. A previous report has described new assay systems which utilize 
zebrafish as a promising model system to study the complex behavior of drug preference [Ninkovic and Bally-Cuif 2006]. Interestingly, in addition to adult zebrafish, larval fish were also shown to display choice behavior towards addictive substances, such as amphetamine and morphine. These behaviors were dissociable from food preference, and could be attenuated by pretreatment with dopamine receptor antagonists or in the too few mutant characterized by a reduction in the selective groups of dopaminergic and serotonergic neurons in the basal diencephalon [Bretaud et al. 2007]. These reports suggest that kinesin expression activity could be used to link gene expression to behavior by establishing a system to evaluate the behavioral response to drugs. Thus, isolation of tissue-specific promoters which replicate endogenous gene expression may contribute to one of the important aims of neuroscience research - linking behavior to molecular and cellular phenomena. 


\section{Experimental procedure}

\subsection{Animals}

Fish were kept and bred in our laboratory as shown previously [Kawasaki 2008]. The larvae were kept in $50 \mathrm{mM} \mathrm{NaCl}$ solution and fed daily with a commercially available feed. The fish, larvae and eggs were kept under a $14: 10 \mathrm{~h}$ light/dark cycle at $26.5 \pm 1^{\circ} \mathrm{C}$. We used See-through II strain [Wakamatsu 2001] and HdrR strain for production of transgenic fish and genomic analysis, respectively.

\subsection{Identification and cloning of medaka neuronal kinesin gene}

Amino acid sequences encoded in kinesin gene reported from human KIF5A(AK294881), human KIF5B (AK289413), mouse (BC090841), and squid (J05258) were aligned and three conserved amino acid sequences were selected to design degenerate primers: KDEVKEV in AK294881 for Kin-FW1 primer (5'-AARGAYGARGTNAARGARGT-3'), IEEEFTV in AK294881 for Kin-FW2 primer (5'-cgatagtcgacATHGARGARGARTTYCANGT-3'), and TKVHHQ in AK294881 for Kin-RV1 primer (reverse primer, 5'-cgtagaattcYTGYTTRTGNACYTTNGT-3') (lower cases are additional nucleotides).

Total RNA was isolated from the brain, skeletal muscle, kidney, and ovary of adult Hd-rR fish with Torizol (Life Technologies), according to the manufacturer's instructions. Complementary DNA (cDNA) was synthesized with 1 ug of total RNA using SuperScript II reverse transcriptase (Invitrogen) with random 9-mer primer. With the resulting cDNA as a template, polymerase chain reaction (PCR) was performed using primers Kin-FW1 and Kin-RV1 with 35 cycles of $94 \mathrm{C}$ for $45 \mathrm{sec}, 40 \mathrm{C}$ for $45 \mathrm{sec}$, and $72 \mathrm{C}$ for $3 \mathrm{~min}$ and then nested PCR was performed using primers Kin-FW2 and Kin-RV1 with 35 cycles of $94 \mathrm{C}$ for $45 \mathrm{sec}, 45 \mathrm{C}$ for $45 \mathrm{sec}$, and $72 \mathrm{C}$ for $2 \mathrm{~min}$.

To screen brain specific kinesin fragment, resulting PCR products from brain, skeletal muscle, kidney, and ovary were subcloned into EcoRI/Sal I site of pBlueScript II KS+ (Stratagene). After amplification of each plasmid in E. Coli (DH5-alpha), each plasmid clone was digested with Hae III and selected clones (neuronal clones) whose digestion pattern were observed only in cDNA derived from brain RNA. By comparison of cDNA sequence with kinesin genes from other mammals, we determined the clones containing medaka neuronal kinesin. 
Coding sequence (CDS) of medaka neuronal kinesin was determined using primer walking method and 5' and 3'-RACE method. In primer walking method, we designated specific primers for neuronal kinesin based on BAC DNA sequence in following section.

\subsection{Determination of gene structure for medaka neuronal kinesin}

Using a neuronal clone (described above) as a probe, a bacterial artificial chromosome (BAC) library of the Hd-rR strain constructed by Matsuda et al [Matsuda et al. 2001] was screened for the neuronal kinesin gene. The DNA sequence of the positive BAC clone was determined by shot gun sequence method by Dragon Genomics rtd (Mie, Japan).

\subsection{Tissue distribution or stage dependency for expression of kinesins}

We investigated tissue distribution or stage dependency for expression of kinesins, according to previous report [Kawasaki 2008]. Briefly, messenger RNA (mRNA) from various tissues of adult Hd-rR fish or whole body of larval Hd-rR fish were extracted with QuickPrep Micro mRNA Purification kit (GE Healthcare). cDNA was synthesized with a First-Strand cDNA Synthesis kit (GE Healthcare) using equal amounts of the mRNAs. Aliquots of each synthesized cDNA were used for PCR with Taq polymerase (HS TAKARA Taq, TAKARA).

The following primers were used: sense 5'ACACCATGGAGGGTAAGCTG-3' and antisense 5'-ACCACAATGGACGAGGAGTC-3' for amplification between 281 and 1223 bp of medaka KIF5Aa ORF (ENSORLT00000004896); sense

5'-ATGGCTGATTCCAACGCTGAA-3' and antisense 5'-
GCTCAGCCTCCAGTTTCTGAAT-3' for amplification between 1 and 1102 bp of medaka KIF5Ab ORF (ENSORLT00000006687); sense 5'-TGACATTGCCGCACTGGTTG-3' and antisense 5'- GCTGGGGAGGAGAAAGTCTGTTTAG-3' for amplification between 77 and $1201 \mathrm{bp}$ of medaka beta-actin cDNA (NM_001104808). PCR products were sequenced and confirmed to be identical to orthologues from the database.

\subsection{Whole mount in situ hybridization}

Whole mount in situ hybridization was performed accoding to a previous report [Deguchi 2009] with slight modification. The 281-1223 region of medaka KIF5Aa ORF was amplified and cloned into pGEM T easy vector (Promega).The direction of gene insertion was confirmed by sequencing, and appropriate restriction enzymes were determined as Sacll, Spel for sense, antisense probe productions, respectively. The digoxigenin (DIG) 
labeled riboprobes were generated with a DIG RNA labeling kit SP6/T7 (Roche Diagnostics GmbH, Mannheim, Germany).

Embryos of the See-through strain, fixed, dehydrated, rehydration, permeabilized, and fixed again, were pre-hybridized in hybridization buffer (HB; $50 \%$ formamide, $5 \times$ SSC, $1.5 \mathrm{mg} / \mathrm{mL}$ Yeast tRNA, $50 \mu \mathrm{g} / \mathrm{mL}$ Heparin, $0.1 \%$ Tween-20) at $60{ }^{\circ} \mathrm{C}$ for $4 \mathrm{~h}$ and hybridized overnight with $1 \mathrm{ng} / \mathrm{uL}$ of each riboprobe in $\mathrm{HB}$ at $60^{\circ} \mathrm{C}$. After incubation in blocking buffer, embryos were incubated overnight with anti-DIG antibody conjugated with alkaline phosphatase (1:5000 dilution, Roche Diagnostics $\mathrm{GmbH}$, Mannheim, Germany) in blocking buffer at $4{ }^{\circ} \mathrm{C}$. Hybridized probes were detected via color reaction with NBT and BCIP. Photomicrographs were captured with a MZ-FLIII binocular microscope (Leica Microsystems GmbH, Wetzlar, Germany) with a color CCD camera (DP-70, Olympus, Tokyo, Japan).

\subsection{Construction of GFP expression vector}

Using the positive BAC clone as a template, 5' and 3' flranking regions of neuronal kinesin CDS were amplified by PCR and inserted into Sal I/Nco I site and Not I/Aat II site of pEGFP (Clontech), respectively.

\subsection{Establishment of transgenic (Tg) medaka strain}

The GFP expression plasmid was injected into fertilized eggs of $d$-rR strain before the first cleavage as described by Kinoshita et al. [Kinoshita et al. 2000]. Obtained Tg medaka was crossed with wild type of See-through fish, and the final $\mathrm{Tg}$ strain was established by selecting fish indicating phenotype similar to wild type of See-through fish.

\subsection{Immunohistochemistry}

Fixed larval fish were cut into $20 \mu \mathrm{m}$ sections, which were equilibrated sequentially with phosphate buffered saline (PBS), tris buffered saline (TBS) and TBS containing $0.2 \%$ Tween 20 (TBST) for 10 min. After incubation in blocking solution (BS; TBST containing $1 \%$ fetal bovine serum (FBS)) at $4{ }^{\circ} \mathrm{C}$, the sections were incubated in 1000 fold diluted anti-HuC/D antibody (16A11, Molecular Probe), 1000 fold diluted anti-GFAP antibody (G-A-5, Sigma) or 2000 fold diluted anti-GFP antibody (GF200, Nacalai tesque) with BS, followed by washing 3 times with TBST for $15 \mathrm{~min}$. The sections were incubated in 500 fold diluted anti-mouse IgG antibody conjugated with Alexa 488 or Alexa 546, followed by washing 
sequentially with TBST, TBS, PBS for 15 min. After dripping mounting medium containing Mowiol 4-48, the sections were enclosed with cover grasses. After drying at 4 degrees overnight, fluorescent images were acquired with confocal laser microscopy.

\subsection{Imaging of transgenic fish}

Embryos and larvae was hold in 1\% low melting point agarose (SIGMA) on glass base dish (0.12-0.17 $\mu \mathrm{m}$ thickness), and covered with enough amount of water to prevent from being dry. Confocal images were taken with Fluoview laser scanning conforcal microscopy (Olympus). EGFP was excited by $488 \mathrm{~nm}$ light from multi argon laser. Emission light of 475-575 was passed through, and detected through the grading. 


\section{Acknowledgements}

We thank Yuko Wakamatsu for providing the See-Through strain for the National Bio-Resource Program. We also thank Yoriko Jouzaki and Kaoru Ogata for maintenance of the fish stocks. This work was supported by the Ministry of Economy, Trade, and Industry (METI). 


\section{References}

Aluru N, Karchner SI, Hahn ME., 2011, Role of DNA methylation of AHR1 and AHR2 promoters in differential sensitivity to PCBs in Atlantic Killifish, Fundulus heteroclitus. Aquat. Toxicol. 101, 288-294.

Bai Q, Burton EA., 2009, Cis-acting elements responsible for dopaminergic neuron-specific expression of zebrafish slc6a3 (dopamine transporter) in vivo are located remote from the transcriptional start site.Neuroscience. 164, 1138-1151.

Berg JS, Derfler BH, Pennisi CM, Corey DP, Cheney RE., 2000, Myosin-X, a novel myosin with pleckstrin homology domains, associates with regions of dynamic actin. J. Cell Sci. 113, 3439-3451.

Brady ST., 1985, A novel brain ATPase with properties expected for the fast axonal transport motor. Nature 317, 73-75.

Bretaud S, Li Q, Lockwood BL, Kobayashi K, Lin E, Guo S., 2007, A choice behavior for morphine reveals experience-dependent drug preference and underlying neural substrates in developing larval zebrafish. Neuroscience. 146, 1109-1116.

Chatterjee R, Vinson C., 2012, CpG methylation recruits sequence specific transcription factors essential for tissue specific gene expression. Biochim Biophys Acta. Feb 23 [Epub ahead of print]

Crimella C, Baschirotto C, Arnoldi A, Tonelli A, Tenderini E, Airoldi G, Martinuzzi A, Trabacca A, Losito L, Scarlato M, Benedetti S, Scarpini E, Spinicci G, Bresolin N, Bassi M., 2011, Mutations in the motor and stalk domains of KIF5A in spastic paraplegia type 10 and in axonal Charcot-Marie-Tooth type 2. Clin. Genet. doi: 10.1111/j.1399-0004.2011.01717.x..

Deguchi T, Fujimori KE, Kawasaki T, Xianghai L, Yuba S., 2009, Expression patterns of the Egr1 and Egr3 genes during medaka embryonic development. Gene Expr. Patterns. 9, 209-214. 
Dhar SS, Wong-Riley MT., 2011, The kinesin superfamily protein KIF17 is regulated by the same transcription factor (NRF-1) as its cargo NR2B in neurons. Biochim. Biophys. Acta. 1813, 403-411.

Ekström P, Johansson K, 2003, Differentiation of ganglion cells and amacrine cells in the rat retina: correlation with expression of HuC/D and GAP-43 proteins. Brain Res. Dev. Brain Res. 145, 1-8.

Elango N, Yi SV., 2008, DNA methylation and structural and functional bimodality of vertebrate promoters. Mol Biol Evol. 25, 1602-1608.

Ghosh S, Yates AJ, Frühwald MC, Miecznikowski JC, Plass C, Smiraglia D., 2010, Epigenetics. Tissue specific DNA methylation of $\mathrm{CpG}$ islands in normal human adult somatic tissues distinguishes neural from non-neural tissues. Epigenetics 5, 527-38.

Gong Y, Ma Z, Patel V, Fischer E, Hiesberger T, Pontoglio M, Igarashi P., 2009, HNF-1 beta regulates transcription of the PKD modifier gene Kif12. J. Am. Soc. Nephrol. 20, 41-47.

Grupp L, Wolburg H, Mack AF., 2010, Astroglial structures in the zebrafish brain. J. Comp. Neurol. 518, 4277-4287.

Hirokawa N, Pfister KK, Yorifuji H, Wagner MC, Brady ST, Bloom GS., 1989, Submolecular domains of bovine brain kinesin identified by electron microscopy and monoclonal antibody decoration. Cell 56, 867-878.

Hirokawa N., 1998, Kinesin and dynein superfamily proteins and the mechanism of organelle transport. Science 279, 519-526.

Hirokawa N, Noda Y., 2008, Intracellular transport and kinesin superfamily proteins, KIFs: structure, function, and dynamics. Physiol. Rev. 88, 1089-1118.

Jung SH, Kim S, Chung AY, Kim HT, So JH, Ryu J, Park HC, Kim CH., 2010, Visualization of myelination in GFP-transgenic zebrafish. Dev. Dyn. 239, 592-597.

Kanai Y, Okada Y, Tanaka Y, Harada A, Terada S, Hirokawa N., 2000, KIF5C, a novel neuronal kinesin enriched in motor neurons. J. Neurosci. 20,6374-6384. 
Kasashima K, Terashima K, Yamamoto K et al, 1999, Cytoplasmic localization is required for the mammalian ELAV-like protein HuD to induce neuronal differentiation. Genes Cells 4, 667-683.

Kawasaki T, Saito K, Deguchi T, Fujimori K, Tadokoro M, Yuba S, Ohgushi H, Kawarabayasi Y., 2008, Pharmacological characterization of isoproterenol-treated medaka fish. Pharmacol Res. 58, 348-355.

Kinoshita M, Kani S, Ozato K, Wakamatsu Y., 2000, Activity of the medaka translational elongation factor 1 alha-A promoter examined using the GFP gene as a reporter. Dev. Growth Differ. 42, 469-478.

Kouzmenko AP, Pereira AM, Singh BS., 1997, Intronic sequences are involved in neural targeting of human dopamine transporter gene expression. Biochem. Biophys. Res. Commun. 240, 807-811.

Matsuda M, Kawato N, Asakawa S, Shimizu N, Nagahama Y, Hamaguchi S, Sakaizumi M, Hori H., 2001, Construction of a BAC library derived from the inbred Hd-rR strain of the teleost fish, Oryzias latiopes. Genes Genet. Syst., 76, 61-63.

Matsushita M, Yamamoto R, Mitsui K, Kanazawa H., 2009, Altered motor activity of alternative splice variants of the mammalian kinesin-3 protein KIF1B. Traffic 10, 1647-1654.

McIntosh JR, Grishchuk EL, West RR., 2002, Chromosome-microtubule interactions during mitosis. Annu. Rev. Cell Dev. Biol. 18, 193-219.

Miki H, Setou M, Kaneshiro K, Hirokawa N., 2001, All kinesin superfamily protein, KIF, genes in mouse and human. Proc. Natl. Acad. Sci. U S A. 98, 7004-7011.

Miki H, Okada Y, Hirokawa N., 2005, Analysis of the kinesin superfamily: insights into structure and function. Trends Cell Biol. 15, 467-476.

Moore A, Wordeman L., 2004, The mechanism, function and regulation of depolymerizing kinesins during mitosis. Trends Cell Biol. 14, 537-546. 
Niclas, J., F. Navone, N. Hom-Booher, and R.D. Vale., 1994, Cloning and localization of a conventional kinesin motor expressed exclusively in neurons. Neuron 12, 1059-1072.

Ninkovic J, Bally-Cuif L., 2006, The zebrafish as a model system for assessing the reinforcing properties of drugs of abuse. Methods. 39, 262-274.

Palaniswamy R, Teglund S, Lauth M, Zaphiropoulos PG, Shimokawa T., 2010, Genetic variations regulate alternative splicing in the 5 ' untranslated regions of the mouse glioma-associated oncogene 1, Gli1. BMC Mol. Biol. 11, 32.

Rivière JB, Ramalingam S, Lavastre V, Shekarabi M, Holbert S, Lafontaine J, Srour M, Merner N, Rochefort D, Hince P, Gaudet R, Mes-Masson AM, Baets J, Houlden H, Brais B, Nicholson GA, Van Esch H, Nafissi S, De Jonghe P, Reilly MM, Timmerman V, Dion PA, Rouleau GA., 2011, KIF1A, an axonal transporter of synaptic vesicles, is mutated in hereditary sensory and autonomic neuropathy type 2. Am. J. Hum. Genet. 89, 219-230.

Takai D, Jones PA., 2002, Comprehensive analysis of CpG islands in human chromosomes 21 and 22., Proc. Natl. Acad. Sci. U S A. 99, 3740-3745.

Tanaka M, Kinoshita M, Kobayashi D, Nagahama Y., 2001, Establishment of medaka (Oryzias latipes) transgenic lines with the expression of green fluorescent protein fluorescence exclusively in germ cells: a useful model to monitor germ cells in a live vertebrate. Proc. Natl. Acad. Sci. U S A. 98, 2544-2549.

Tarabeux J, Champagne N, Brustein E, Hamdan FF, Gauthier J, Lapointe M, Maios C, Piton A, Spiegelman D, Henrion E; Synapse to Disease Team, Millet B, Rapoport JL, Delisi LE, Joober R, Fathalli F, Fombonne E, Mottron L, Forget-Dubois N, Boivin M, Michaud JL, Lafrenière RG, Drapeau P, Krebs MO, Rouleau GA., 2010, De novo truncating mutation in Kinesin 17 associated with schizophrenia. Biol. Psychiatry. 68, 649-656.

Uveges TE, Shan Y, Kramer BE, Wight DC, Parysek LM., 2002, Intron 1 is required for cell type-specific, but not injury-responsive, peripherin gene expression. J. Neurosci. 22, 7959-7967.

Wang J, Bannon MJ., 2005, Sp1 and Sp3 activate transcription of the human dopamine transporter gene. J. Neurochem. 93, 474-482. 
Wakamatsu Y, Pristyazhnyuk S, Kinoshita M, Tanaka M, Ozato K., 2001, The see-through medaka: a fish model that is transparent throughout life. Proc. Natl. Acad. Sci. U S A. 98, 10046-10050.

Wang L, Brown A., 2010, A hereditary spastic paraplegia mutation in kinesin-1A/KIF5A disrupts neurofilament transport. Mol. Neurodegener. 5, 52.

Xia, C., A. Rahman, Z. Yang, and L.S.B. Goldstein., 1998, Chromosomal localization reveals three kinesin heavy chain genes in mouse. Genomics 52, 209-213.

Yamamoto H, Imai K, Kamegaya E, Takamatsu Y, Irago M, Hagino Y, Kasai S, Shimada K, Yamamoto T, Sora I, Koga H, Ikeda K., 2006, Repeated methamphetamine administration alters expression of the NMDA receptor channel epsilon2 subunit and kinesins in the mouse brain. Ann. N. Y. Acad. Sci. 1074, 97-103.

Yoshida M, Macklin WB., 2005, Oligodendrocyte development and myelination in GFP-transgenic zebrafish., J. Neurosci. Res. 81, 1-8.

Yu Y, Feng YM., 2010, The role of kinesin family proteins in tumorigenesis and progression: potential biomarkers and molecular targets for cancer therapy. Cancer. 116, 5150-5160.

Zhao C, He X, Tian C, Meng A., 2006, Two GC-rich boxes in huC promoter play distinct roles in controlling its neuronal specific expression in zebrafish embryos. Biochem. Biophys. Res. Commun. 342, 214-220.

Zhou L, Nian M, Gu J, Irwin DM., 2006, Intron 1 sequences are required for pancreatic expression of the human proglucagon gene. Am. J. Physiol. Regul. Integr. Comp. Physiol. 290, R634-41. 


\section{Figure legends}

Figure 1

A. Phylogenic analysis of the cloned medaka kinesin.

UCSC genome database was used to obtain amino acid sequences of KIF5 family from various species. The sequence data were aligned with clustal $X$ and phylogenic tree was described with NJ-plot. The used sequences are following; human KIF5A (AAI50209.1), human KIF5B (AAI26282.1), human KIF5C (NP_004513.1), mouse KIF5A (AAH58396.1), mouse KIF5B (AAH90841.1), mouse KIF5C (AAH67051.1), rat KIF5A (NP_997688.1), rat KIF5B (NP_476550.1), rat KIF5C (NP_001101200.1), chicken KIF5C (XP_422155.2), xenopus KIF5A (AAI36118.1), xenopus KIF5B (AAI67608.1), zebrafish KIF5Aa (NP_001186705.1), and medaka kinesin. Nomenclature of the zebrafish orthologue was according to zebrafish genome database, zfin. A medaka neuronal kinesin cloned in this study, indicated as medaka.nkinesin, was categorized in KIF5A. The numbers indicate branch lengths.

B. Comparison of KIF5A orthologues.

Amino acid sequences of KIF5A orthologues from species containing human, mouse, rat, xenopus, zebrafish and medaka fish were aligned with clustal X. Asterisks represent identical residues in all species. Single or double dots represent weakly or highly conserved residues, respectively. "-" characters indicate gaps. Gray bar under sequences indicates homology among species. Blue double-headed arrow indicates motor domain, red indicates PEST sequence predicted by Genetyx.

Figure 2

mRNA levels for medaka KIF5A.

Medaka KIF5A mRNA levels in adult medaka fish were analyzed by RT-PCR. (A) Tissue distribution analysis was performed using mRNAs from various tissues of adult Hd-rR strain fish, as following; Br: brain, Sc: spinal cord, He: heart, Li: liver, Sp: spleen, Ki: kidney, In: intestine, Gi: gill, Sk: skeletal muscle, Te: testis, Ov: overy. KIF5Aa exhibited neuronal tissue specific expression, while expression of KIF5Ab was restricted in neuronal tissues, spleen and testis. As for KIF5Ab, only the PCR products $\left(^{*}\right)$ obtained in $\mathrm{Br}$, Sc, and $\mathrm{Sp}$ were reproductive and their nucleotide sequence were identical with that of KIF5Ab.

(B) Stage dependency analysis was performed using mRNAs from whole larval fish in various stages. The PCR reactions for KIF5As were run for 40 cycles. The reaction for beta-actin was run for 25 cycles. 
Figure 3

A. Genomic synteny for human and medaka KIF5A genes.

Genomic synteny of medaka KIF5a, KIF5Ab and human KIF5A. The figure was described on the basis of displays by UCSC browser. Red or blue means genes similar between medaka KIF5Aa or KIF5Ab and human KIF5A, respectively.

B. Organization of the medaka KIF5Aa gene and the pnkine-GFP vector.

Black boxes on the upper line denote the exons of the medaka KIF5Aa gene. pnkine-GFP was composed of an enhanced GFP (EGFP, Clontech) flanked by the $5^{\prime}$ region (6.9 kb) upstream of start codon, indicated as ATG and the $3^{\prime}$ region (1.9 kb) downstream of stop codon of medaka KIF5Aa gene

Figure 4

WISH analysis of KIF5Aa gene expression

The analysis was performed using $6 \mathrm{dpf}$ larval fish, as described in Methods. a, b, c and d represent overhead, rear, frontal and sagittal views of head, respectively. e, $f$ represent overhead and sagittal views of trunk, respectively. Spinal cords are indicated by sc. g, h, i represent negative controls against $\mathrm{a}, \mathrm{d}$, e, respectively. Bar indicates $100 \mu \mathrm{m}$.

Figure 5

Phenotype of Tg strain: pnkine-GFP.

A. Earliest expression of EGFP.

Earliest EGFP expression in the $\mathrm{Tg}$ fish was observed in trigeminal ganglion $(\mathrm{a}, \mathrm{b})$ and spinal cord (c, d) at 3.5 daf. Right images were magnified from the area encompassed by white squares in left images. Bars indicate $100 \mu \mathrm{m}$ in a and $\mathrm{c}$, and $50 \mu \mathrm{m}$ in $\mathrm{b}$ and $\mathrm{d}$.

B. Neuronal tissue specific expression of EGFP in Tg fish.

EGFP expression at 30 daf was observed in whole of central nervous system, including telencephalon (te), olfactory pit (op), habenula (hb), mesencephalon (me), pineal gland (pg), torus longitudinalis (tl), cerebellum (cb), medulla, and spinal cord (sc). No expression appeared in non-neuronal tissues. Bars indicate $200 \mu \mathrm{m}$ in a, and $50 \mu \mathrm{m}$ in b, c, d, e and f.

C. EGFP expression in spinal cord and the surroundings.

Sagittal (a) and overhead views (b) of $\mathrm{Tg}$ fish was observed at 14 daf. EGFP expressed in spinal cord (sc), sympathetic trunk (st) and motor neurons, indicated by asterisks. Bars indicate $50 \mu \mathrm{m}$.

D. EGFP expression in peripheral nervous system.

$\mathrm{Tg}$ fish were observed at 7 daf (a) and 14 daf (b,c). EGFP expression was also observed in eye (a), olfactory pit (c) and cranial nerves (c; arrowheads). Immunohistchemical analysis of 
eye with cross section showed that EGFP was localized in optic nerve (on) and retina (re) (b). Bars indicate $100 \mu \mathrm{m}$ in a and $50 \mu \mathrm{m}$ in $\mathrm{b}$ and $\mathrm{c}$.

Figure 6

Immunohistochemical analysis of EGFP expressing cells in Tg fish. Transverse sections of $\mathrm{Tg}$ fish midbrain (upper) or spinal cord (lower) were used for the analysis to verify co-localization of EGFP with HuC/D. Arrowheads indicate cells being anti-HuC/D-positive but anti-EGFP-negative. Bars indicate $50 \mu \mathrm{m}$. 


\section{Fig.1 A}

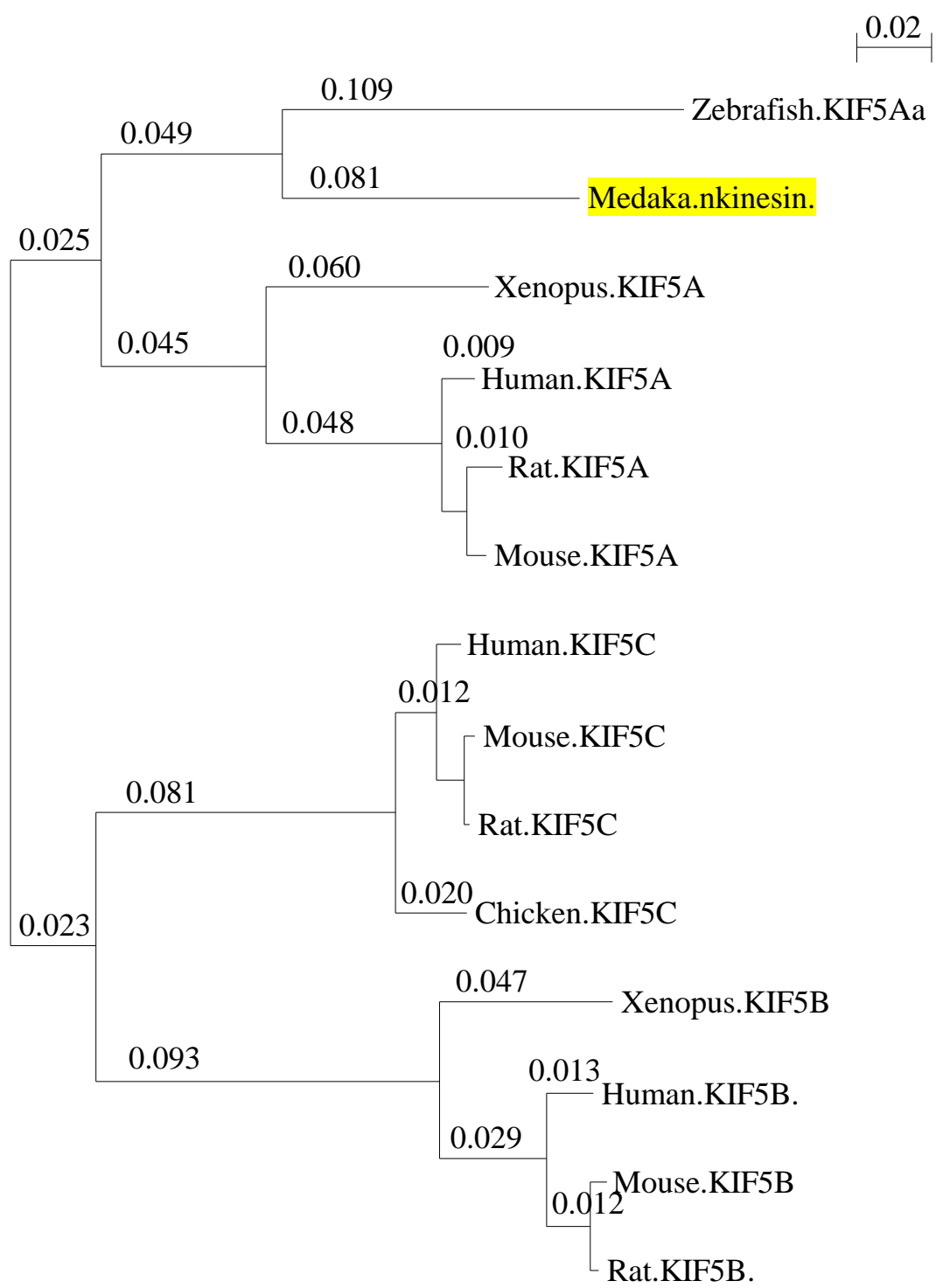


Fig. $1 \mathrm{~B}$

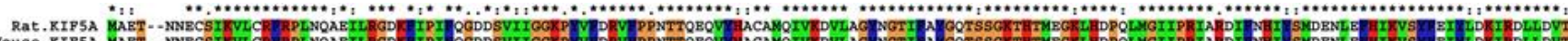

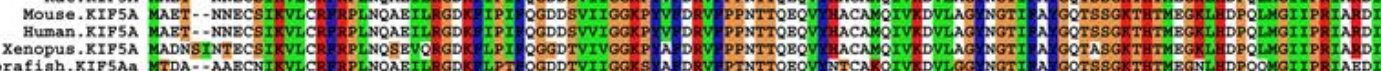

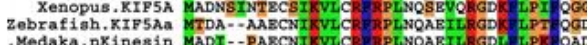

$$
\text { 1. }
$$

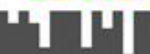

14T

17

Rat. KIF5A
Mouse.KIF5A
Buman.KIF5A Zebrafish. KIF5Aa
- Medaka.nKinesin

, I, 11 1 $11+20$

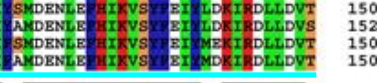

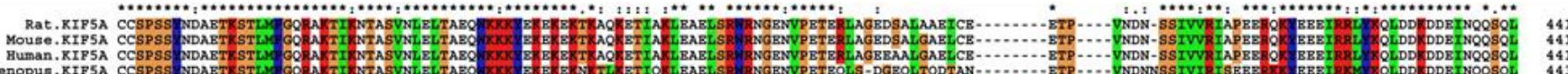

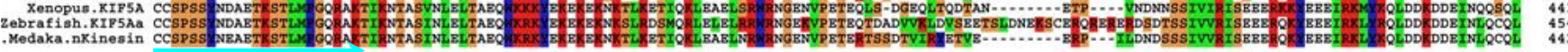



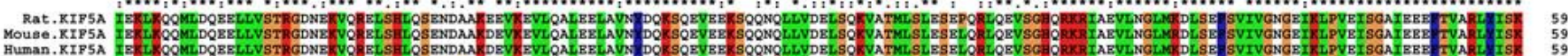

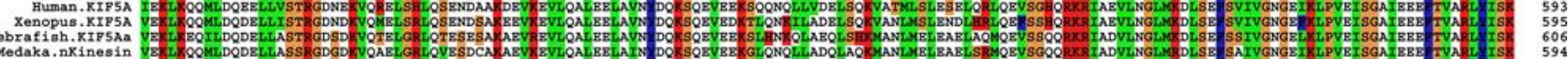

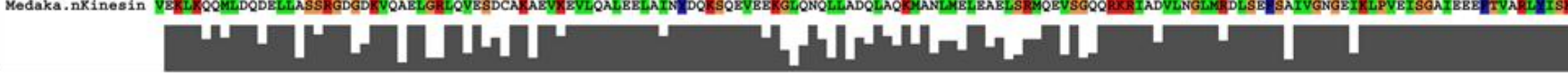

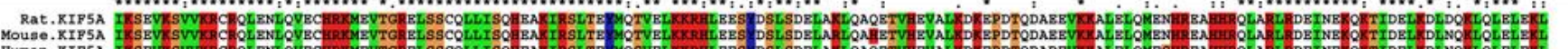

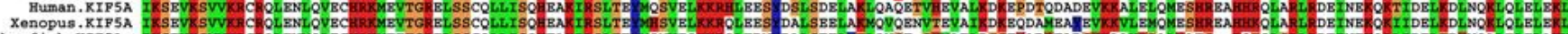

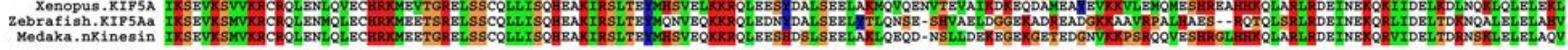

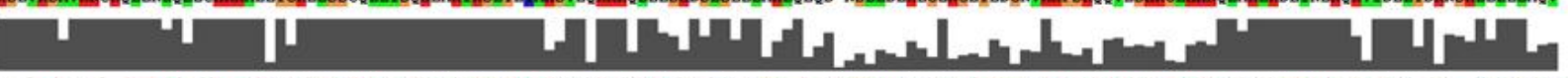

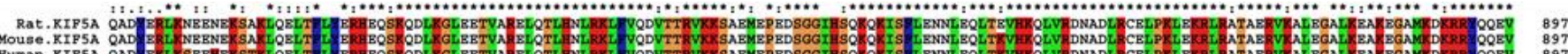

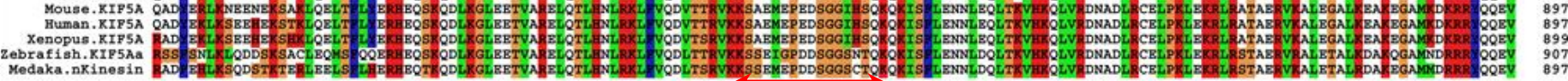



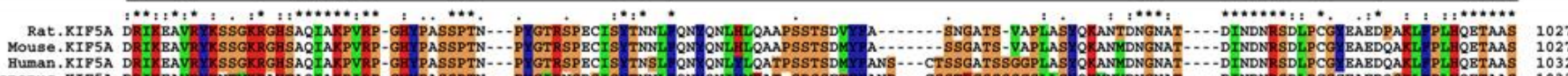

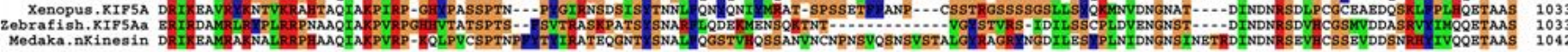
" " 


\section{Fig.2 A}

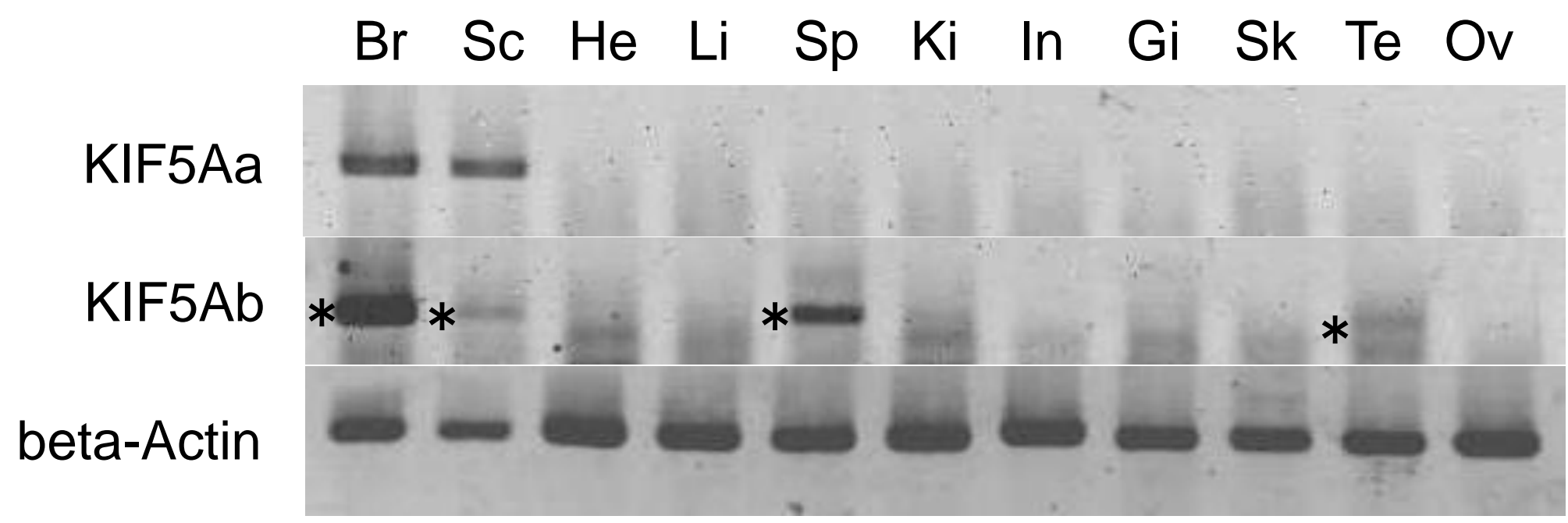

Fig.2 B

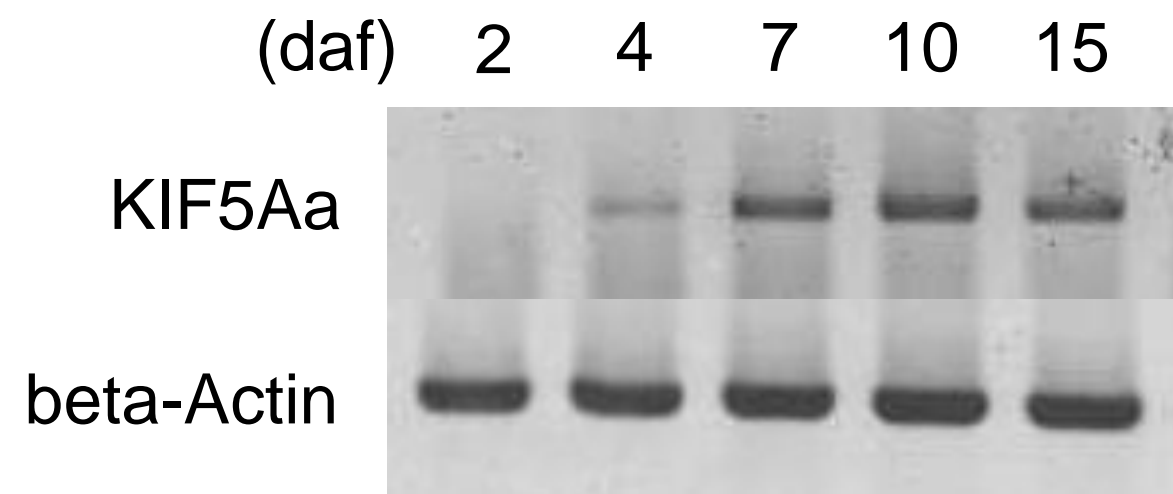




\section{Fig.3 A}

medaka KIF5Aa

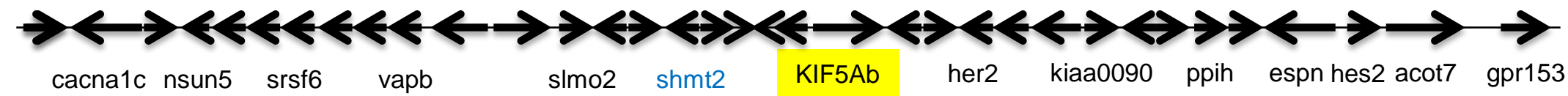

chdh tkt sgk2 eif2s2 gnas slc32a1 rnu5e-1 stac3 tas1r1 ubr4 taf10 ybx1

I3mbt11 chmp4b piezo2 actr5 rnu5a-1 rprd1b hes3 pht4

medaka KIF5Ab

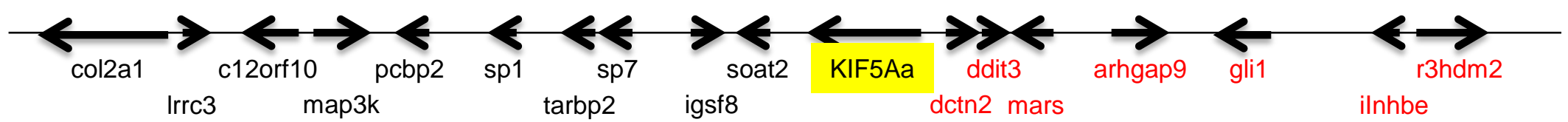

human KIF5A

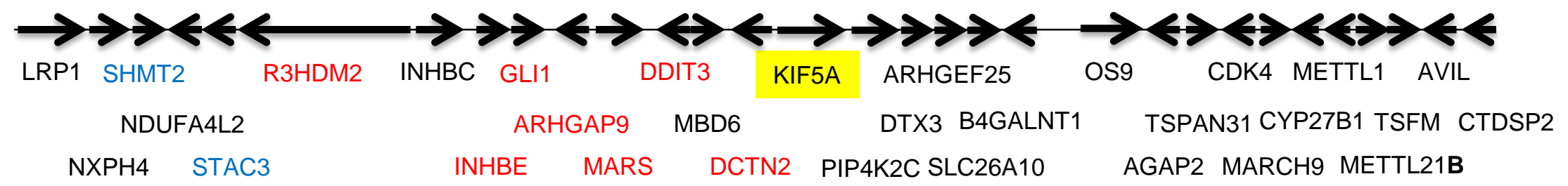




\section{Fig.3 B}

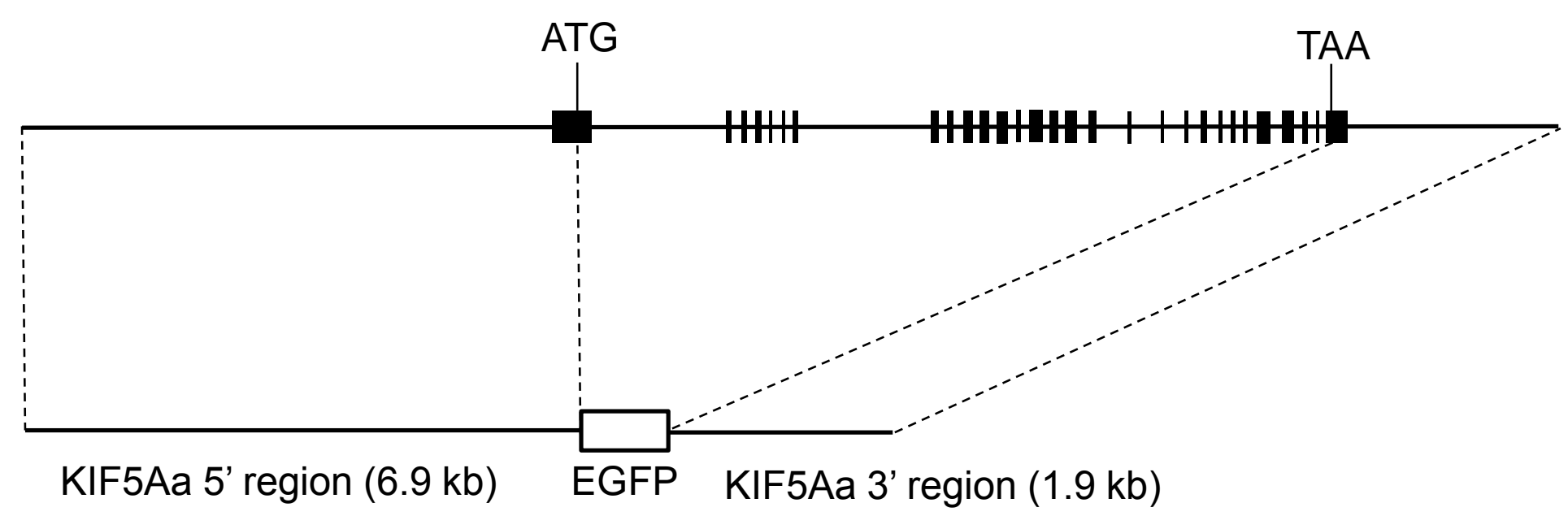


28. 京都大学

Fig.4

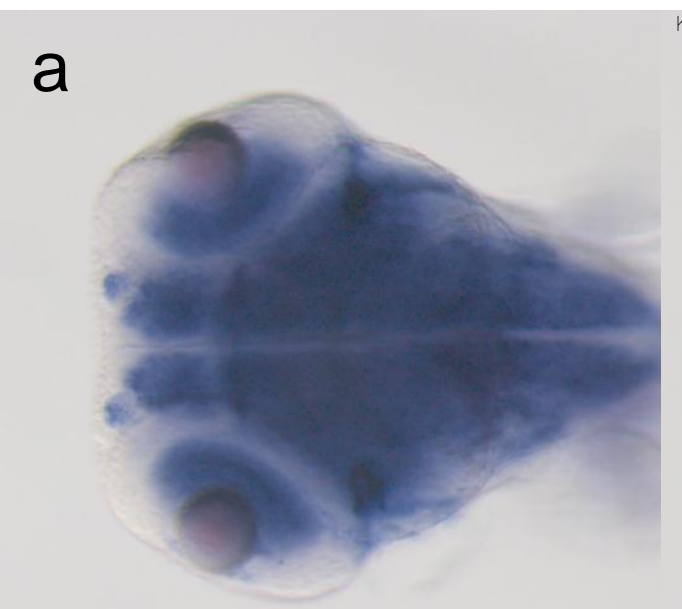

b

g

C

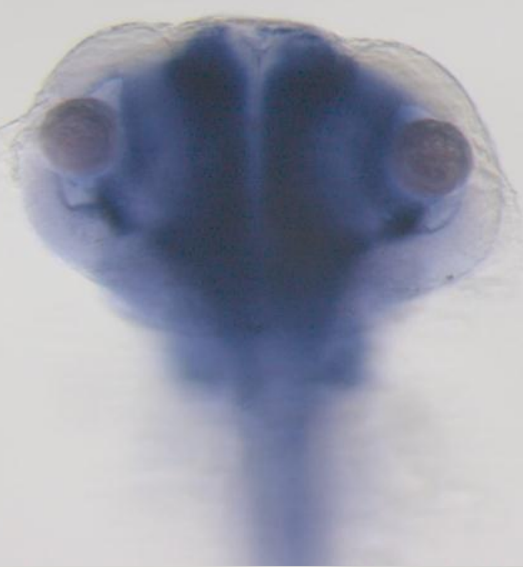

e

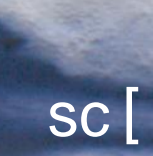

d

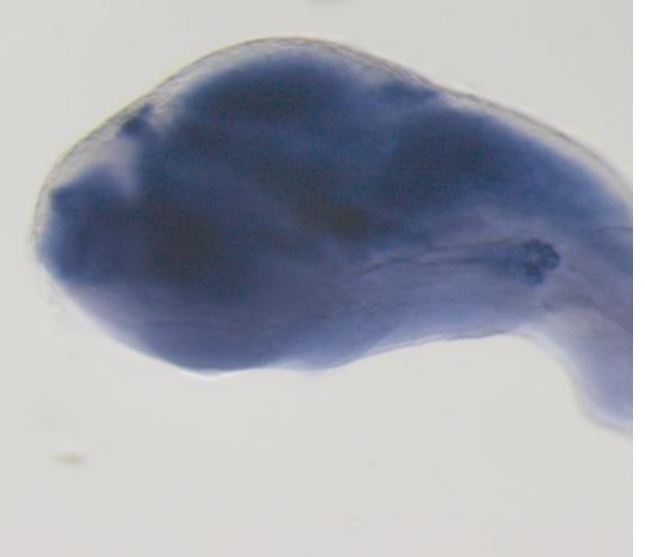

f

SC I

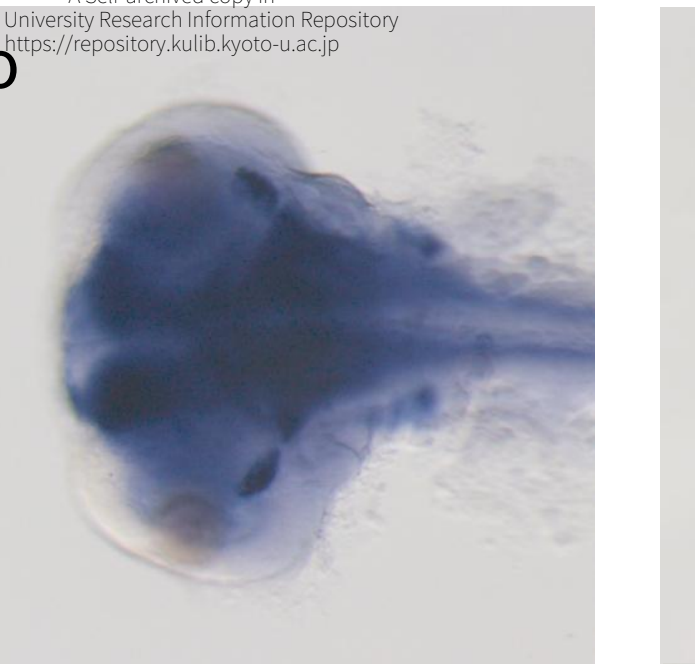

h

i

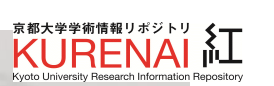
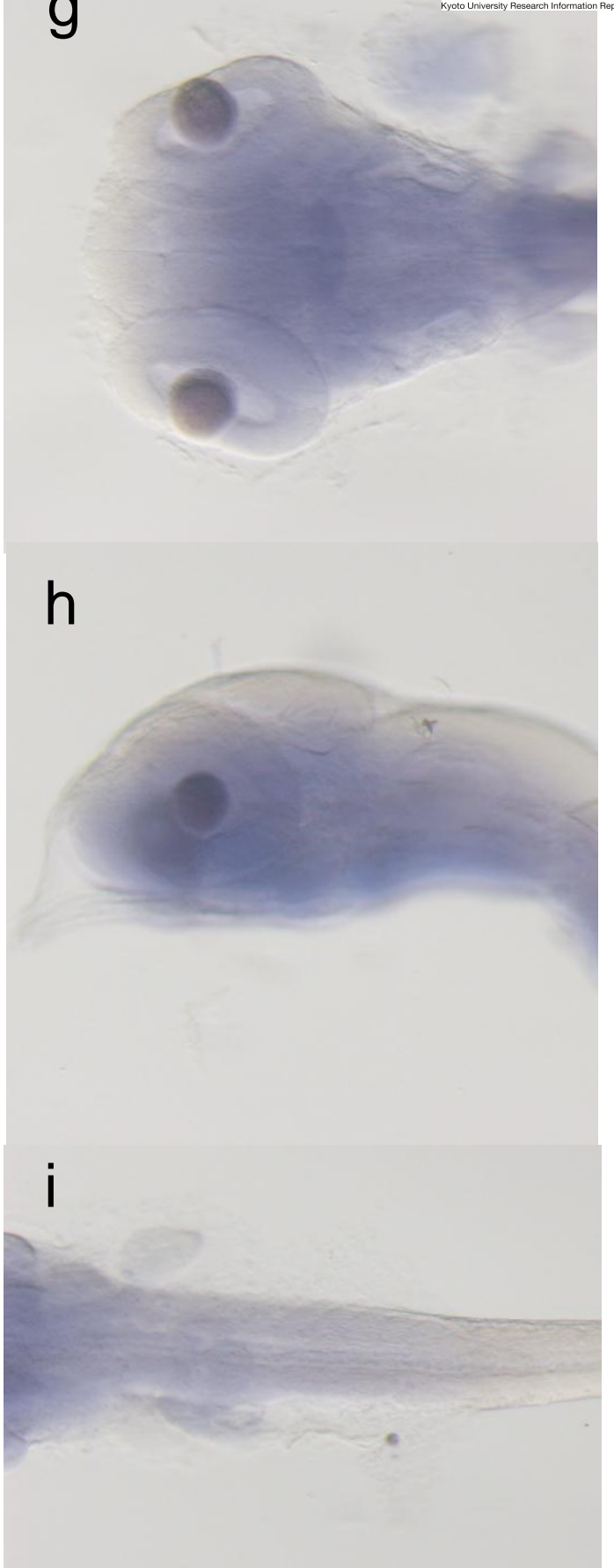
Fig. $5 \mathrm{~A}$

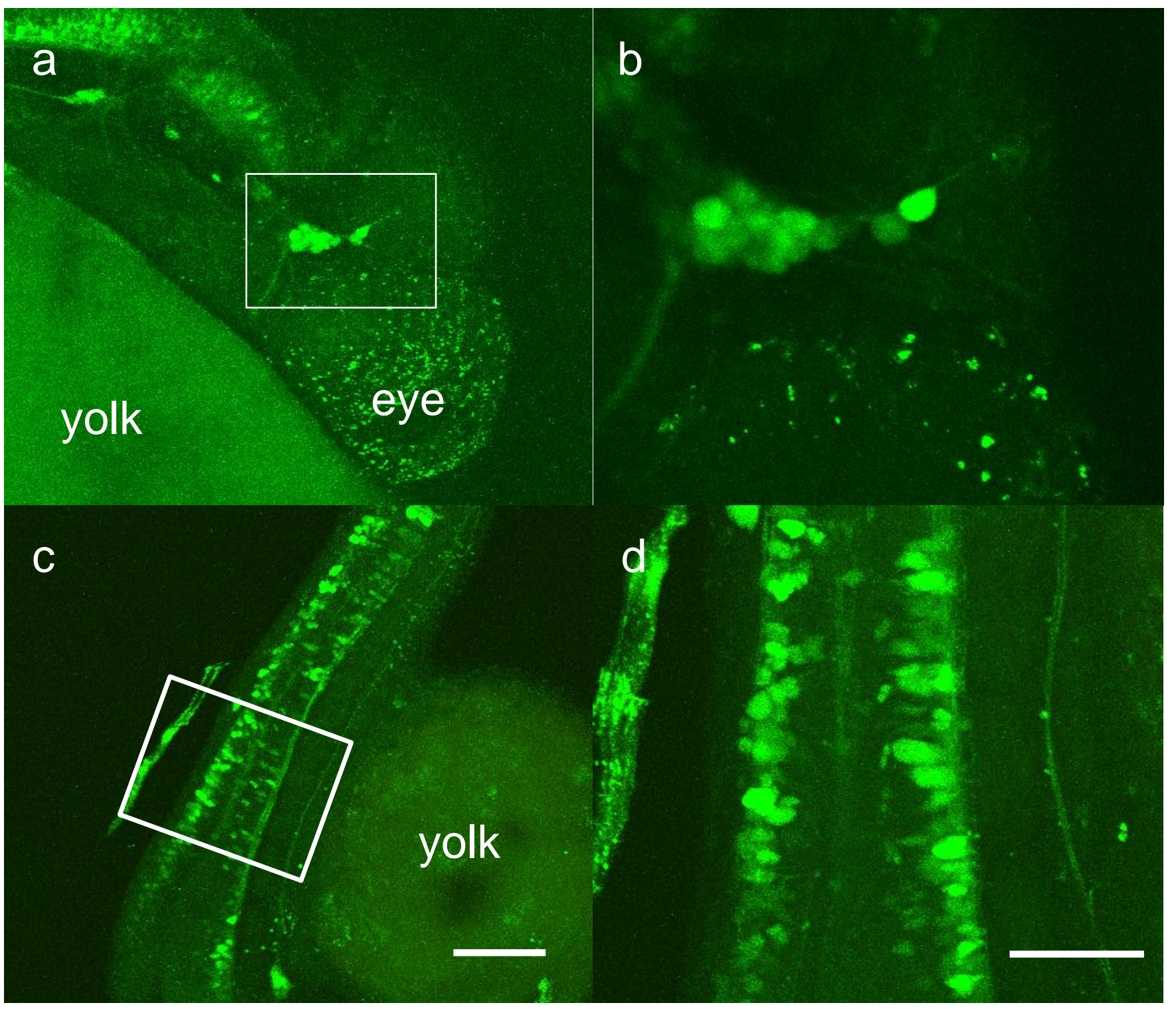


Fig.5 B
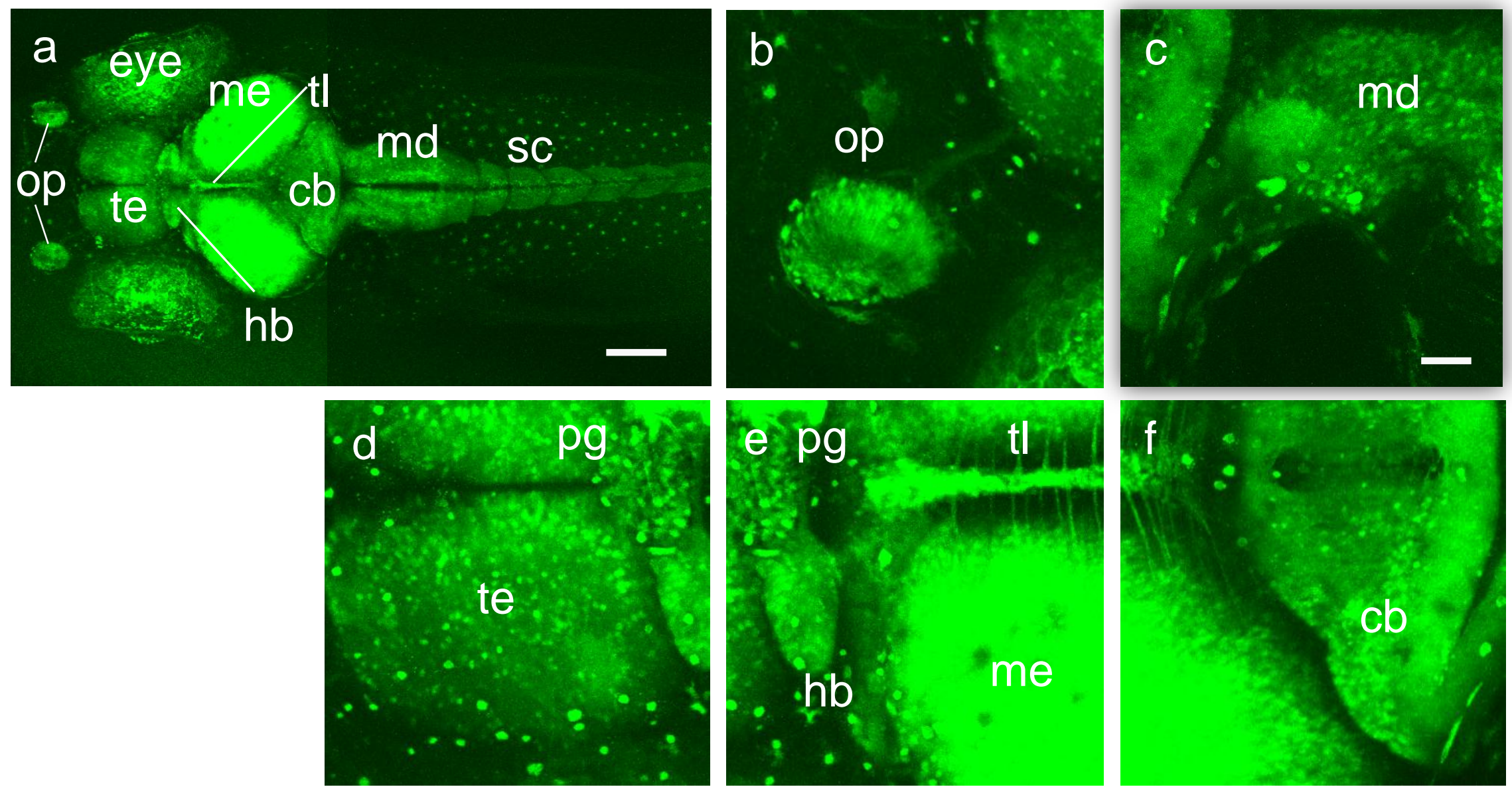
Fig.5 C

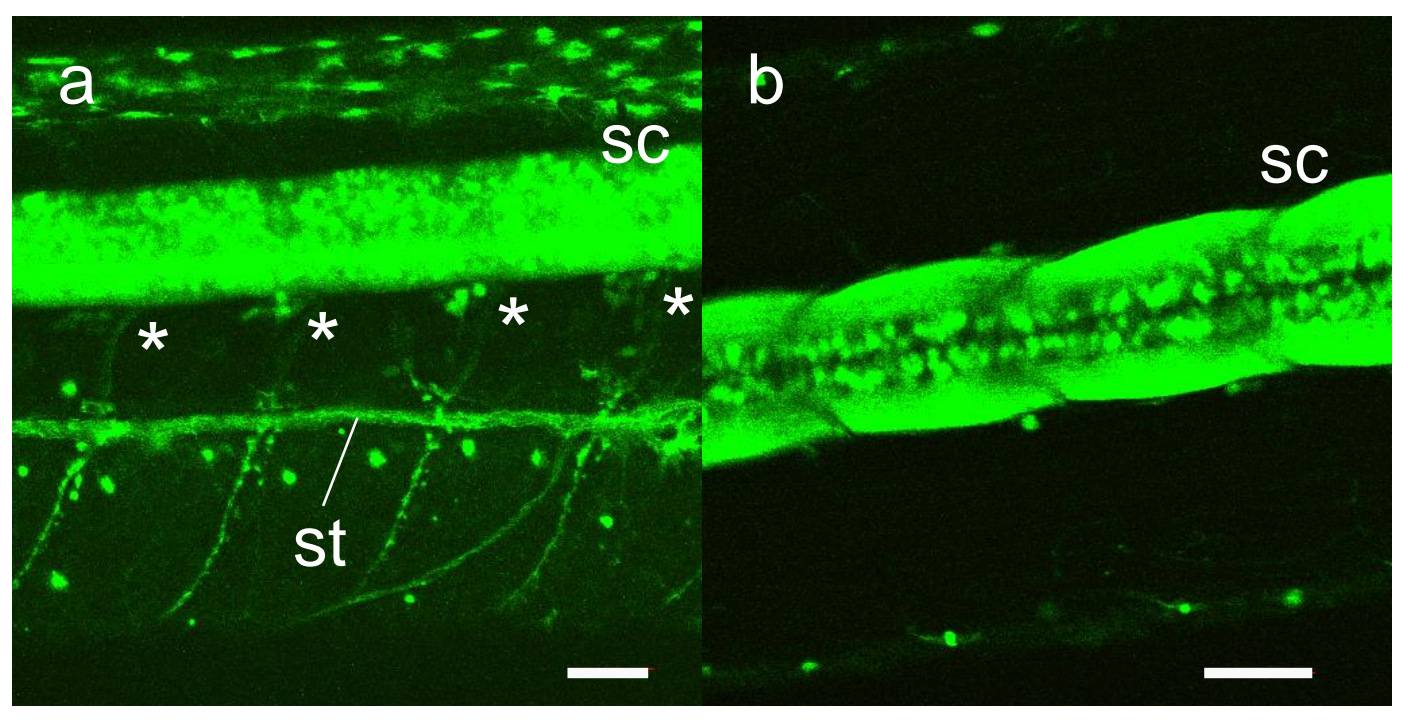

Fig.5 D

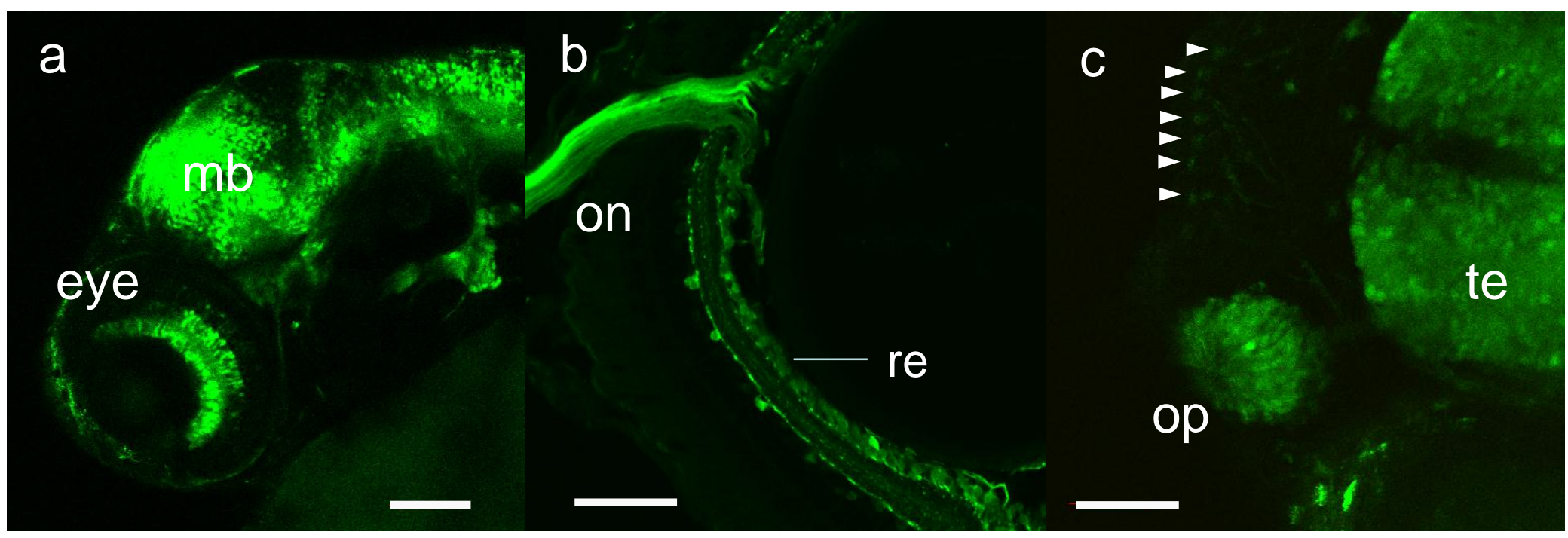


Fig.6

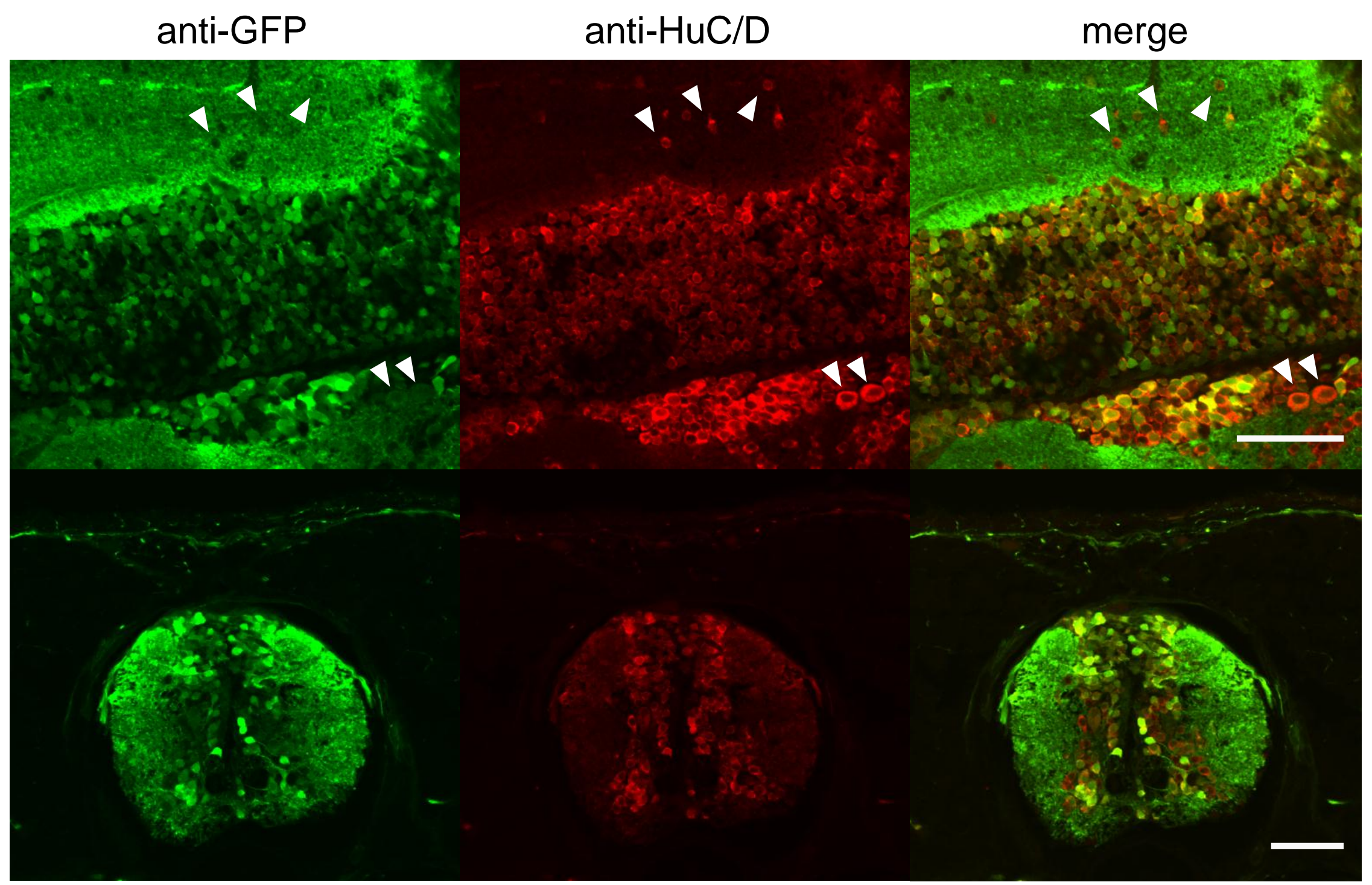

